\title{
Role of GABA Deficit in Sensitivity to the Psychotomimetic Effects of Amphetamine
}

\author{
Kyung-Heup Ahn 1,2,3, Andrew Sewell ${ }^{1,2,3}$, Jacqueline Elander ${ }^{1,2,3}$, Brian Pittman ${ }^{2,3}$, Mohini Ranganathan ${ }^{1,2,3}$, \\ Handan Gunduz-Bruce ${ }^{1,3}$, John Krystal ${ }^{1,2,3}$ and Deepak Cyril D'Souza ${ }^{*, 1,2,3}$ \\ 'Psychiatry Service, VA Connecticut Healthcare System, West Haven, CT, USA; ${ }^{2}$ Abraham Ribicoff Research Facilities, Connecticut Mental Health \\ Center, West Haven, CT, USA; ${ }^{3}$ Department of Psychiatry, Yale University School of Medicine, West Haven, CT, USA
}

\begin{abstract}
Some schizophrenia patients are more sensitive to amphetamine (AMPH)-induced exacerbations in psychosis-an effect that correlates with higher striatal dopamine release. This enhanced vulnerability may be related to gamma-aminobutyric acid (GABA) deficits observed in schizophrenia. We hypothesized that a pharmacologically induced GABA deficit would create vulnerability to the psychotomimetic effects to the 'subthreshold' dose of AMPH in healthy subjects, which by itself would not induce clinically significant increase in positive symptoms. To test this hypothesis, a GABA deficit was induced by intravenous infusion of iomazenil (IOM; $3.7 \mu \mathrm{g} / \mathrm{kg}$ ), an antagonist and partial inverse agonist of benzodiazepine receptor. A subthreshold dose of AMPH $(0.1 \mathrm{mg} / \mathrm{kg})$ was administered by intravenous infusion. Healthy subjects received placebo IOM followed by placebo $\mathrm{AMPH}$, active $\mathrm{IOM}$ followed by placebo $\mathrm{AMPH}$, placebo IOM followed by active $\mathrm{AMPH}$, and active IOM followed by active AMPH in a randomized, double-blind crossover design over 4 test days. Twelve healthy subjects who had a subclinical response to active AMPH alone were included in the analysis. Psychotomimetic effects (Positive and Negative Syndrome Scale (PANSS)), perceptual alterations (Clinician Administered Dissociative Symptoms Scale (CADSS)), and subjective effects (visual analog scale) were captured before and after the administration of drugs. IOM significantly augmented AMPH-induced peak changes in PANSS positive symptom subscale and both subjective and objective CADSS scores. There were no pharmacokinetic interactions. In conclusion, GABA deficits increased vulnerability to amphetamine-induced psychosis-relevant effects in healthy subjects, suggesting that pre-existing GABA deficits may explain why a subgroup of schizophrenia patients are vulnerable to AMPH.
\end{abstract} Neuropsychopharmacology (20I5) 40, 2822-283I; doi:I0.1038/npp.20I5.I32; published online 3 June 2015

\section{INTRODUCTION}

Psychostimulants such as amphetamine and methylphenidate when administered at high doses and/or repeatedly produce transient psychosis characterized by positive symptoms and thought disorder in healthy individuals (Griffith et al, 1968; Angrist and Gershon, 1970; Bell, 1973; Janowsky and Risch, 1979; Bartlett et al, 1991). However, schizophrenic patients are more vulnerable to the effects of psychostimulants. Schizophrenic patients experience psychotic exacerbations with single, modest doses of psychostimulants (Lieberman et al, 1987b), and the magnitude of the psychotomimetic effects of amphetamine is greater in schizophrenic patients than in healthy subjects (Janowsky et al, 1973; Koreen et al, 1997; Lieberman et al, 1987b). However, the amphetamine response in schizophrenia is heterogenous. While some patients showed worsening of symptoms ( $40 \%)$, improvement of symptoms and

*Correspondence: Professor DC D'Souza, Psychiatry Service, VA Connecticut Healthcare System, 950 Campbell Avenue, West Haven, CT 065।6, USA, Tel: +| 860203932 57। I, Fax: + | 860203937 4860, E-mail: Deepak.dsouza@yale.edu

Received 17 December 2014; revised 26 March 2015; accepted 20 April 2015; accepted article preview online 8 May 2015 no effect of amphetamine were also observed in others (Lieberman et al, 1987b).

Consistent with the amphetamine-induced symptom exacerbation in some schizophrenia patients observed in earlier psychopharmacological challenge studies, more recent imaging studies have revealed significantly higher amphetamine-induced striatal dopamine (DA) release in schizophrenic patients relative to healthy controls (Abi-Dargham et al, 1998; Abi-Dargham et al, 2009; Breier et al, 1997; Laruelle et al, 1996). Furthermore, DA release correlated with the amphetamine-induced increases in psychosis. One possible explanation for the enhanced amphetamine sensitivity in some schizophrenia patients might be related to the well-documented gamma-aminobutyric acid (GABA) deficits observed in the disorder (Lewis et al, 2005), and the important interplay between the DA and GABA systems (Carr and Sesack, 2000; Sesack et al, 2003; Tam and Roth, 1990; Tzschentke, 2001; Van Bockstaele and Pickel, 1995).

Release of DA is under GABAergic influence. Fifteen to twenty percent of cells in the ventral tegmental area (VTA) contain GABA (Kalivas, 1993). GABAergic interneurons exert an inhibitory tone on midbrain dopaminergic neurons via several different pathways. First, DA neurons in VTA receive two major glutamatergic excitatory inputs, one from 
the prefrontal cortex and the other from the brain stem lateral dorsal/pendunculopontine tegmentum (Sesack et al, 2003; Tzschentke, 2001). Dopamine neurons in the substantia nigra receive an additional glutamatergic input from the subthalamic nucleus (Sesack et al, 2003; Tzschentke, 2001). GABA neurons in the prefrontal cortex dampen the activity of glutamatergic projections to the tegmental pedunculopontine nucleus (Sesack et al, 2003; Tzschentke, 2001), and thus indirectly inhibit midbrain DA cells. Second, there exist both GABA-A and GABA-B receptors in VTA DA neurons, which exert direct inhibitory input (Tam and Roth, 1990). Third, in VTA and substantia nigra, there are small number of GABA neurons that project to the same brain area with DA neurons (Carr and Sesack, 2000; Van Bockstaele and Pickel, 1995), which implicates their modulatory effects on the target areas of these dopaminergic projections.

Converging lines of evidence, including postmortem (Benes, 2000; Benes and Berretta, 2001; Hashimoto et al, 2003; Lewis et al, 2005; Ohnuma et al, 1999; Volk et al, 2000; Volk and Lewis, 2002a; Volk et al, 2002b; Woo et al, 1998), genetic (reviewed by Cherlyn et al (2010)), and brain imaging studies (Ball et al, 1998; Busatto et al, 1997; Kegeles et al, 2012; Ongur et al, 2010; Schroder et al, 1997; Verhoeff et al, 1999; Yoon et al, 2010), suggest that the dysfunction of the GABA system may contribute to the pathophysiology of schizophrenia. The results of in vivo magnetic resonance spectroscopy studies are mixed with some studies reporting elevations (Kegeles et al, 2012; Ongur et al, 2010), reductions (Rowland et al, 2013; Yoon et al, 2010) or no differences (Goto et al, 2009; Tayoshi et al, 2010) in GABA levels in specific brain regions of schizophrenia patients relative to controls. Some, but not all, in vivo receptor imaging studies suggest reduced benzodiazepine receptor binding in schizophrenia (Ball et al, 1998; Busatto et al, 1997; Schroder et al, 1997; Verhoeff et al, 1999). Several post-mortem studies have revealed evidence of pre- and postsynaptic abnormalities in specific GABAergic interneurons, namely the parvalbumin-positive basket cells, resulting in a reduction in the inhibitory control of pyramidal cells (Lewis et al, 2012; Lewis et al, 2005).

This study tested the hypothesis that inducing GABA deficits in healthy subjects would increase the psychotomimetic effects of amphetamine. More specifically, we hypothesized that in healthy individuals who do not experience clinically significant positive symptoms in response to a low dose of amphetamine would do so in the presence of a pharmacologically modeled GABAergic deficit.

\section{MATERIALS AND METHODS}

In a four test day, double-blind, placebo-controlled, randomized, crossover and counterbalanced study, healthy volunteers received active iomazenil followed by active amphetamine, active iomazenil followed by placebo amphetamine, placebo iomazenil followed by active amphetamine, and placebo iomazenil followed by placebo amphetamine. The study was conducted in the Neurobiological Studies Unit (VA Connecticut Healthcare System (VACHS), West Haven, CT).

\section{Approvals}

The study was approved by the institutional review boards of the Veterans Affair Health Care System, West Haven, CT (VAHCS-WH) and Yale University School of Medicine and was carried out in accordance with the Helsinki Declaration of 1975. The study was carried out under Investigational New Drug applications (75 099). Subjects were informed about the potential for adverse effects of amphetamine, iomazenil, and the combination.

\section{Participants}

Healthy male subjects aged between 18 and 55 were recruited by word of mouth, and public advertisement, and compensated $\$ 250$ per test day for participating, for a total of $\$ 1000$ for the four test days. Female subjects were excluded from this study because the teratogenic potential of iomazenil has not been studied. Potential subjects underwent a thorough medical and psychiatric history, complete physical examination, and a battery of laboratory tests including electroencephalogram (EEG), electrocardiogram (ECG), blood chemistry ( $\mathrm{CBC}, \mathrm{BUN}$, creatinine, fasting blood glucose, electrolytes, liver and thyroid function tests, and VDRL), and urinalysis. Subjects underwent a structured psychiatric interview for DSM-IV and were screened for any DSM-IV Axis I or Axis II lifetime psychiatric or substance abuse disorder. Those who were treated with any psychotropic medication were excluded. The history provided by subjects was confirmed by a telephone interview conducted with an individual (spouse or family member) who was identified by the subject before screening. Given the proconvulsant potential of iomazenil, a baseline EEG was obtained and evaluated by a qualified neurologist (RAS). Those with an abnormal EEG at screening and a personal or family history of seizure disorder were excluded from the study.

As defined elsewhere (D'Souza et al, 2005), clinically significant positive symptoms were operationalized as higher than 3-point increase in the positive-symptom subscale in Positive and Negative Syndrome Scale (PANSS). The use of a threshold score has been reported by us in several other studies (Abi-Saab et al, 2002; D'Souza et al, 2006; D'Souza et al, 2004) and was used here to only include subjects who were not responsive to amphetamine alone.

\section{Study Drugs}

Both amphetamine and iomazenil solution were prepared by the VACHS-WH Research Pharmacy Service. Iomazenil solution was prepared as described elsewhere (D'Souza et al, 2006). Before use, product concentration was verified using high-performance liquid chromatography and tested for sterility and pyrogenicity.

\section{Amphetamine}

The most commonly utilized intravenous dose of amphetamine in human psychopharmacologic infusion studies is $\sim 0.3 \mathrm{mg} / \mathrm{kg}$ or $\sim 20 \mathrm{mg}$ (Lieberman et al, 1987a). At this dose, (Laruelle et al, 1996) have demonstrated an estimated $7.6 \%$ and $19.5 \%$ increase in striatal DA release in healthy subjects and schizophrenia patients, respectively. 
Furthermore, the increase in striatal DA release also correlated with an increase in PANSS positive symptom subscale scores. On the basis of the study hypothesis that iomazenil would potentiate the effects of amphetamine, a dose of amphetamine in this study $(0.1 \mathrm{mg} / \mathrm{kg})$ that was not expected to produce clinically significant psychosis ( $>3$ point PANSS-positive-subscale score; Abi-Saab et al, 2002; D'Souza et al, 2006; D'Souza et al, 2004) was chosen.

\section{Iomazenil}

Iomazenil has high affinity and selectivity for benzodiazepine receptors $\left(K_{\mathrm{d}}=0.5 \mathrm{nM}\right.$; Johnson et al, 1990). Iomazenil (Ro 16-0154) is an iodine analog of the benzodiazepine receptor-competitive antagonist flumazenil. Some of its pharmacologic properties are comparable to those of flumazenil (Beer et al, 1990). However, unlike the competitive antagonist flumazenil, which blocks the effects of benzodiazepine agonists but lacks intrinsic pharmacological effects (Hunkeler et al, 1981), inverse agonists have intrinsic pharmacological effects opposite to those of benzodiazepines (Tallman and Gallager, 1985). In preclinical studies iomazenil has been shown to behave as a benzodiazepine receptorcompetitive antagonist with inverse agonist effects (Abel et al., 2003; Beer et al, 1990; Schubiger and Hasler, 1989). Similarly, clinical studies demonstrate that iomazenil has anxiogenic effects and at higher doses has proconvulsant effects (Randall, personal communication, 1995) that are consistent with inverse agonist activity at benzodiazepine receptors. Iomazenil produces a net deficit in GABA function. Consistent with a role of GABA deficits in the pathophysiology of psychosis, iomazenil has been shown to increase the psychotomimetic effects of the 5-HT-2 partial agonist, 1-(m-chlorophenyl)piperazine ( $m$-CPP) in healthy subjects (D'Souza et al, 2006), and schizophrenia patients are more vulnerable to the propsychotic effects of iomazenil (Ahn et al, 2011). Iomazenil was administered intravenously at a dose of $3.7 \mu \mathrm{g} / \mathrm{kg}$ over $10 \mathrm{~min}$. At this dose, iomazenil causes an estimated $25 \%$ benzodiazepine receptor occupancy in nonhuman primates (Innis et al, 1991). This has also been shown to be safe and well-tolerated in both healthy subjects and to enhance vulnerability to drug-induced psychotomimetic effects (D'Souza et al, 2006).

\section{Experimental Design}

Subjects completed four test days in randomized, doubleblind, crossover, and counterbalanced design. Each test day was separated by at least $72 \mathrm{~h}$ in order to minimize any carryover effects. Subjects were instructed to refrain from using alcohol, street drugs, psychotropic medications, or caffeinated beverages for 2 weeks before testing and throughout the entire study. Urine toxicology on each test day ruled out recent drug use and a positive screen resulted in exclusion from the study. On each day, subject received either Iomazenil $(3.7 \mu \mathrm{g} / \mathrm{kg})$ or placebo infusion over $10 \mathrm{~min}$, which was followed by either amphetamine $(0.1 \mathrm{mg} / \mathrm{kg})$ or placebo bolus infusion over $1 \mathrm{~min}$ (see Table 1: Schedule of procedures). After amphetamine infusion, ECG was monitored by a physician up to $1 \mathrm{~h}$. Vital signs were monitored at $-90,-20,-11,-1,1,5,30,70,130$, and $190 \mathrm{~min}$ after amphetamine bolus. All subjects who complete the study were contacted at 1 week, and 3 and 6 months after completing the study to detect any changes in their physical or mental health.

\section{Measures}

The primary outcomes included the psychotic symptoms measured using the positive-symptom subscale of the PANSS (Kay et al, 1989) and perceptual alterations measured using the subject-rated and clinician-rated subscales of the Clinician Administered Dissociative Symptoms Scale (CADSS; Bremner et al, 1998) that were administered at baseline, 5, 70, 130, and $190 \mathrm{~min}$ after amphetamine infusion. On the morning of each test day, the rater used the PANSS to assess the past 3 days in order to establish a baseline. Following that every subsequent assessment is for the time period since the last assessment. Furthermore, one item of the PANSS (passive/apathetic social withdrawal) that is not relevant to the context of an acute psychopharmacological challenge was dropped.

Anxiety, drowsiness, high, irritability, sadness, energy level, depressed mood, fearfulness, anger, and tiredness were assessed using a visual analog scale. The same research coordinators rated all four test days for each subject. Interrater reliability sessions were conducted every 1-2 months over the time period ( $\sim 4$ years) that this study was conducted and intraclass correlation coefficients for the PANSS were consistently greater than 0.85 .

\section{Statistical Analysis}

Initially, data were examined descriptively using the means, SDs, and graphs. As per the study protocol, subjects with higher than 3-points increase in PANSS-positive-symptom subscale induced by amphetamine alone were excluded. Normal probability plots and Kolmogorov-Smirnov test statistics revealed that PANSS, CADSS, and VAS outcomes were not normally distributed. Furthermore, the absence of sufficient variance during the placebo administration necessitated the use of a nonparametric approach for repeated measures data (Brunner et al, 2002), where the data were first ranked, and then fitted using a mixed effects model with an unstructured variance-covariance matrix and $P$-values adjusted for ANOVA-type statistics (ATS). For each outcome, we analyzed the peak change from baseline, given that drug-induced behavioral and subjective changes occurred primarily at the +5 min time point (see Figure 1) with limited variability elsewhere. Each model included drug condition as a 4-level, within-subject factor: (1) amphetamine and iomazenil, (2) amphetamine and placebo, (3) iomazenil and placebo, and (4) placebo and placebo. However, unlike behavioral and subjective effects, heart rate and blood pressure effects were not restricted to a single time point, the analysis included all time points. Analyses of other subscales of the PANSS were subjected to adjustment for multiple comparisons. Bonferroni correction was applied within but not across hypotheses. For example, for PANSS general and negative symptom subscales, a cutoff of $0.05 / 2=0.025$ was used to declare significant effects. Vital signs were normally distributed and analyzed using repeated measure ANOVA. All statistical analyses were performed in SAS, version 9.3 (Cary, NC). 
Table I Schedule of Procedures

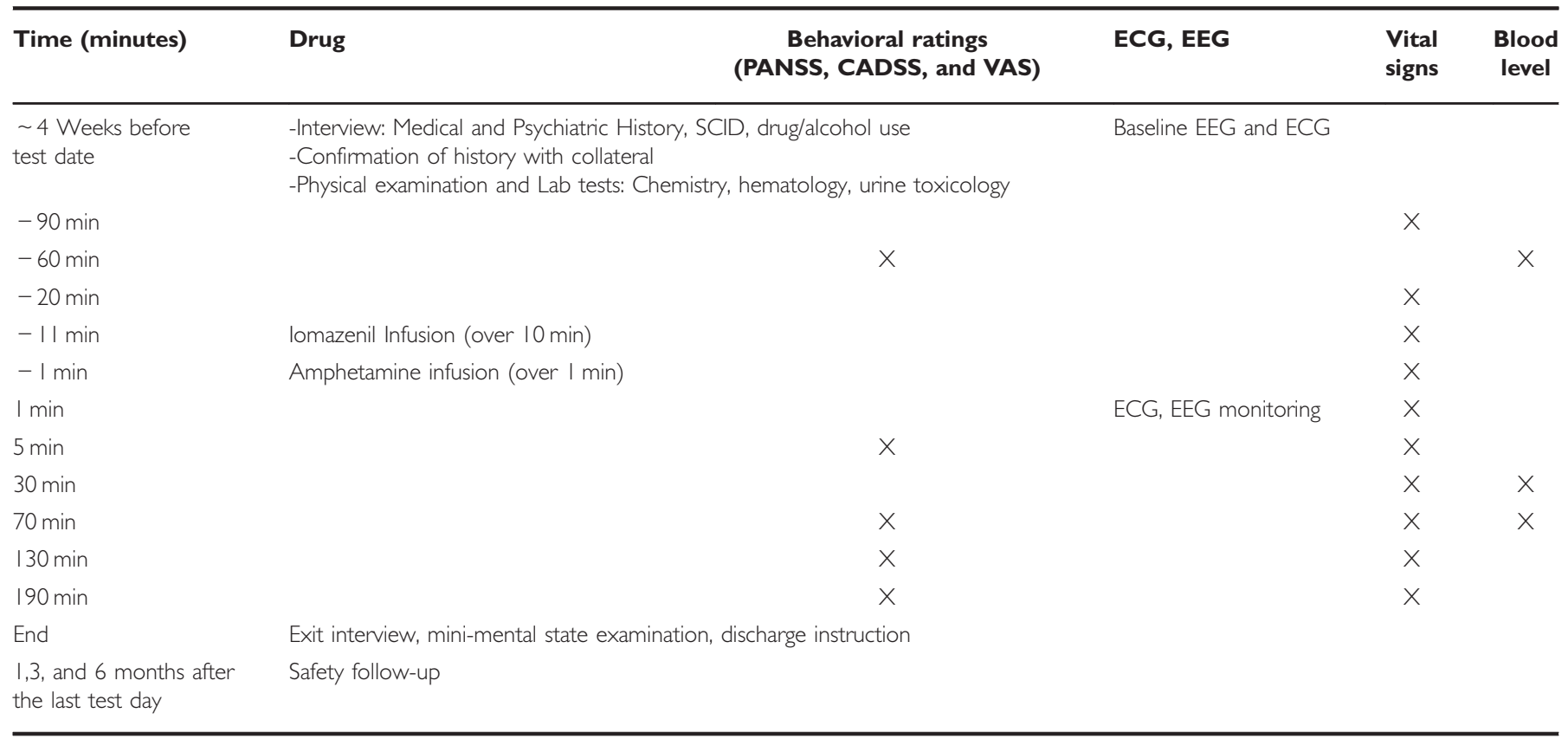

Abbreviations: CADSS, Clinician Administered Dissociative Symptoms Scale; ECG, echocardiogram; EEG, electroencephalography; PANSS, Positive and Negative Syndrome Scale; SCID, Structured Clinical Interview for DSM Disorders; VAS, Visual Analog Scale.
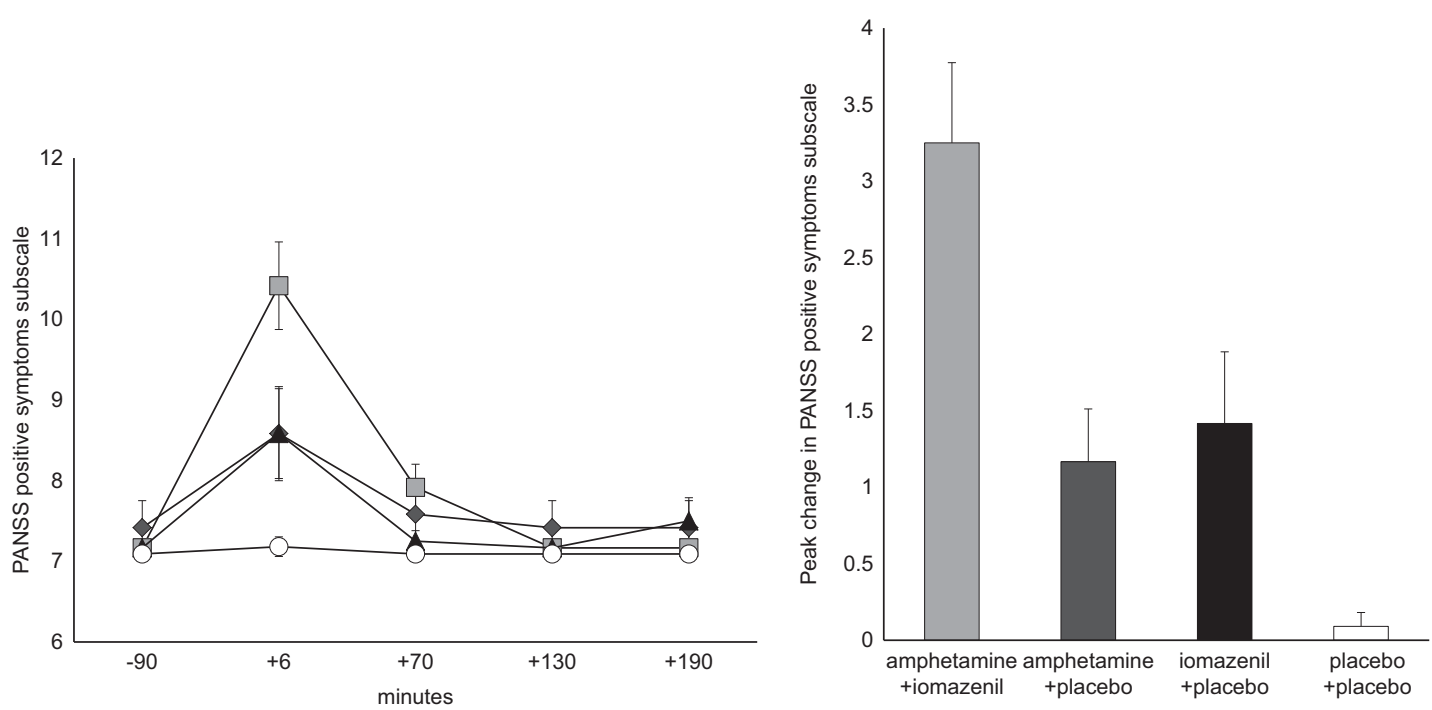

Figure I Effects of amphetamine and iomazenil on Positive and Negative Syndrome Scale (PANSS)-positive symptoms subscale. $\square$ amphetamine+ iomazenil, $\diamond$ amphetamine+placebo, $\boldsymbol{\Delta}$ iomazenil+placebo, and o placebo+placebo.

\section{RESULTS}

Among 18 male subjects who were recruited, 12 subjects met all the study criteria. One subject dropped out on the first day after iomazenil/placebo infusion and was excluded. Five subjects showed higher than 3-point increase in PANSSpositive symptom subscale score and was excluded. One subject dropped out after three test days without completing the fourth test day, which was the placebo-placebo condition. The subjects were $26.2 \pm 6.5$ years old and weighed $187.9 \pm 22.7$ pounds. Ten were Caucasians and two were Asians.

\section{Amphetamine and Iomazenil Levels}

There was no significant difference in the amphetamine plasma level between amphetamine+placebo condition $(19.4 \pm 3.48 \mathrm{ng} / \mathrm{ml})$ and amphetamine+iomazenil condition 
Table 2 lomazenil and Amphetamine Effects on Behavioral Measures

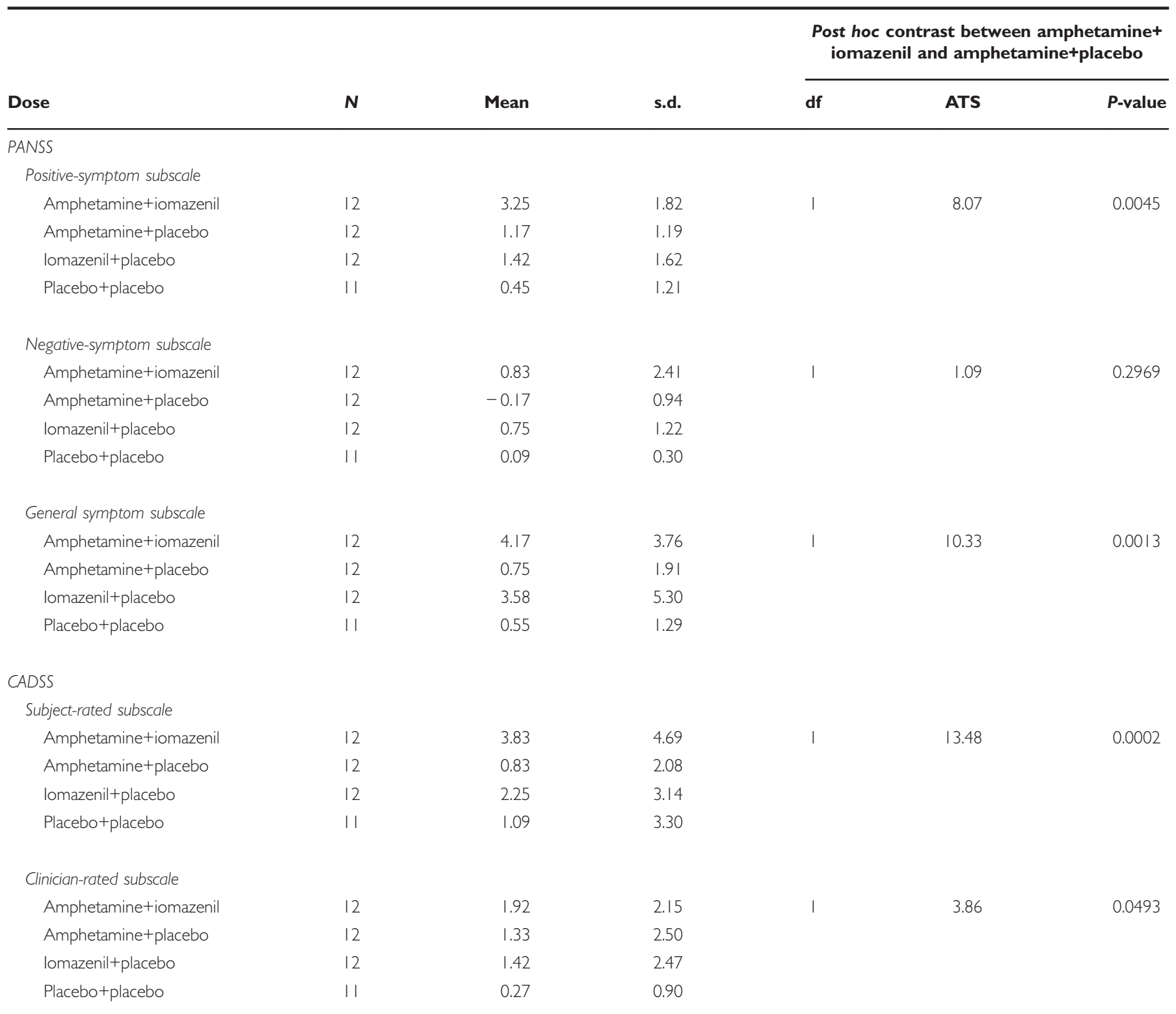

Mixed effects model with an unstructured variance-covariance matrix and P-values adjusted for ANOVA-type statistics. Post hoc contrasts performed only if dose effect is significant.

$(21.2 \pm 5.76 \mathrm{ng} / \mathrm{ml}, \quad t=0.920, \mathrm{df}=10, P=0.279)$ at $30 \mathrm{~min}$ when the primary outcome measures were collected (Supplementary Figure 1A). There was no significant difference in the iomazenil plasma level between iomazenil+placebo condition $(5.11 \pm 2.02 \mathrm{ng} / \mathrm{ml})$ and amphetamine+iomazenil condition $(6.03 \pm 2.80 \mathrm{ng} / \mathrm{ml}, t=-1.257, \mathrm{df}=6, P=0.256)$ at 30 min (Supplementary Figure 1B).

\section{Behavioral Measures}

As the primary hypothesis was that the combination of iomazenil and amphetamine would produce greater changes than amphetamine alone, for parsimony, only the contrasts between the two are reported.

\section{Positive Symptoms}

There was a significant effect of dose on the peak change in PANSS positive symptom subscale score (ATS $=8.78$, $\mathrm{df}=2.41, P<0.0001)$. The peak increase in PANSS positive symptom subscale score induced by amphetamine+ iomazenil $(3.25 \pm 1.82)$ was greater than the effect of amphetamine+placebo $(1.16 \pm 1.19)$ or iomazenil+placebo $(1.41 \pm 1.62$; Figure 1, Table 2). Post hoc analysis revealed significant differences between the amphetamine+iomazenil and amphetamine + placebo conditions (ATS $=8.07, \mathrm{df}=1$, $P=0.0045$, Table 2). Furthermore, $50 \%$ of subjects scored higher than a 3-point increase (PANSS-positive-symptom subscale) on the iomazenil+amphetamine condition. 
Analysis of the interactions between iomazenil (placebo and active) and amphetamine (placebo and active) on the peak change in PANSS-positive-symptom scores was not significant

\section{Negative Symptoms}

There was no significant effect of dose on the peak change in PANSS-negative-symptom subscale score.

\section{General Psychopathology Symptoms}

There was a significant effect of dose on the peak change in the PANSS general psychopathology subscale score (ATS = 6.22, $\mathrm{df}=2.15, \quad P=0.0015)$. Post hoc analysis revealed significant differences between the amphetamine+iomazenil combination and amphetamine+placebo condition (ATS $=10.3, \mathrm{df}=1, P=0.0013)$.

\section{Perceptual Alterations}

There were significant effects of dose on the peak changes in both CADSS subject-rated and clinician-rated subscale scores $(\mathrm{ATS}=6.77, \mathrm{df}=2.45, P=0.0005 ; \mathrm{ATS}=4.3, \mathrm{df}=$ 2.53, $P=0.0078$, respectively). Post hoc analysis revealed significant differences between the amphetamine+iomazenil and amphetamine+placebo conditions for both the subjectrated ( $\mathrm{ATS}=13.48, \mathrm{df}=1, P=0.0002)$ and clinician-rated subscales $(\mathrm{ATS}=3.86, \mathrm{df}=1, P=0.0493)$.

Visual analog scale. There were significant effects of dose on the peak changes in drowsiness $(\mathrm{ATS}=3.44, \mathrm{df}=2.23$, $P=0.0273)$, high $(\mathrm{ATS}=3.28, \mathrm{df}=2.02, P=0.0373)$, and energy (ATS $=3.25$, $\mathrm{df}=2.44, P=0.0293$; Table 3 ). However, there were no significant differences between the amphetamine+iomazenil and amphetamine+placebo conditions in post hoc analyses.

\section{Safety}

Given the potential for iomazenil to lower seizure threshold, all subjects had a baseline EEG to rule out any evidence of seizure-like activity and the first five subjects had realtime continuous EEG monitoring by a qualified neurologist (RAS) during each test for $\sim 1 \mathrm{~h}$ after iomazenil administration. As no seizure-like activity was observed, continuous EEG monitoring was no longer necessary. There were significant dose $\times$ time interaction in systolic blood pressure $(\mathrm{F}(27,413)=3.19, \quad P<0.001), \quad$ diastolic blood pressure $(\mathrm{F}(27,413)=1.85, P=0.0065)$, and heart rate $(\mathrm{F}(27,413)=$ $2.32, P=0.0003)$, which was driven by amphetamine administration (Supplementary Figure 2). There were no significant difference between the amphetamine+iomazenil and amphetamine+placebo conditions in post hoc analyses. None of the subjects reported adverse effects when questioned 1 week, and 3 and 6 months after the last participation date.

\section{DISCUSSION}

To our knowledge, this is the first study in humans examining the interactions between the GABA and DA systems on psychosis-relevant outcomes using a pharmacological approach. In summary, in healthy subjects without any obvious risk of psychosis, iomazenil unmasked the psychotomimetic and perceptual altering effects of a dose of amphetamine that on its own did not produce these effects. The unmasking effect of iomazenil cannot be explained by a simple pharmacokinetic interaction since there were no differences in amphetamine blood levels across the two conditions. In addition, the unmasking effect of iomazenil on amphetamine effects was specific to positive symptoms (PANSS positive symptom subscale) and quasi-positive symptoms (CADSS) as evidenced by a lack of such effects on a range of other measures that are known to be sensitive to amphetamine effects including anxiety, euphoria ('high'), energy level, and cardiovascular effects (systolic and diastolic blood pressures and heart rate).

As described earlier, iomazenil produces a net GABA deficit. Studies investigating iomazenil's effects on psychosis have consistently shown that iomazenil-induced GABA deficits can create vulnerability to psychosis, but does not directly induce psychotic symptoms. The administration of iomazenil alone showed no significant effects on PANSS and CADSS in this study, which is consistent with our previous studies in healthy subjects (Ahn et al, 2011; D'Souza et al, 2006) with the same dosing regimen of iomazenil. Collectively, these three studies $(n=48)$ clearly demonstrate that iomazenil alone does not induce significant increases in measures of psychosis and perceptual alterations in healthy subjects. These data suggest that a GABA deficit alone, as modeled by iomazenil, is not sufficient to induce psychosis. However, when administered to stable, antipsychotic-treated schizophrenia patients iomazenil produced small increases in psychotic symptoms. Furthermore, as observed in this study, iomazenil increased the psychotic symptoms induced by amphetamine and, as shown previously by us, iomazenil increased the psychotic symptoms induced by $\mathrm{m}-\mathrm{CPP}$ in healthy subjects (D'Souza et al, 2006). Similarly, iomazenil has been shown to increase psychosis induced by delta-9-tetrahydrocannabinol (in review). Collectively, these studies suggest that GABA deficits confer vulnerability to psychosis related to perturbations of several receptor systems relevant to psychosis including DA, cannabinoid, and serotonin.

Whereas this study was not designed to inform the mechanism of the precise interactions between iomazenil and amphetamine, several lines of preclinical data suggest potential mechanisms. GABA-A receptor antagonists, including picrotoxin (Theile et al, 2011) and bicuculline (Westerink et al, 1996), disinhibit VTA-DA release. Similarly, GABA-A receptor inverse agonist, FG7142, has been shown to activate VTA neurons (Murphy et al, 1996). FG7142-induced VTA activation was reversed by DA receptor antagonists. Although admittedly speculative, administration of GABA-A receptor antagonists or inverse agonists would be predicted to increase DA release by drugs such as amphetamine. This would be consistent with the findings of the current study showing that iomazenil increased the DA-related symptomatology induced by amphetamine. It will be interesting to follow-up this behavioral study with an imaging study of whether iomazenil increases amphetamine-induced DA release as indexed by displacement of [11C]-raclopride. 


\section{GABA, dopamine and psychosis}

K-H Ahn et al

Table 3 lomazenil and Amphetamine Effects on Subjective Effects

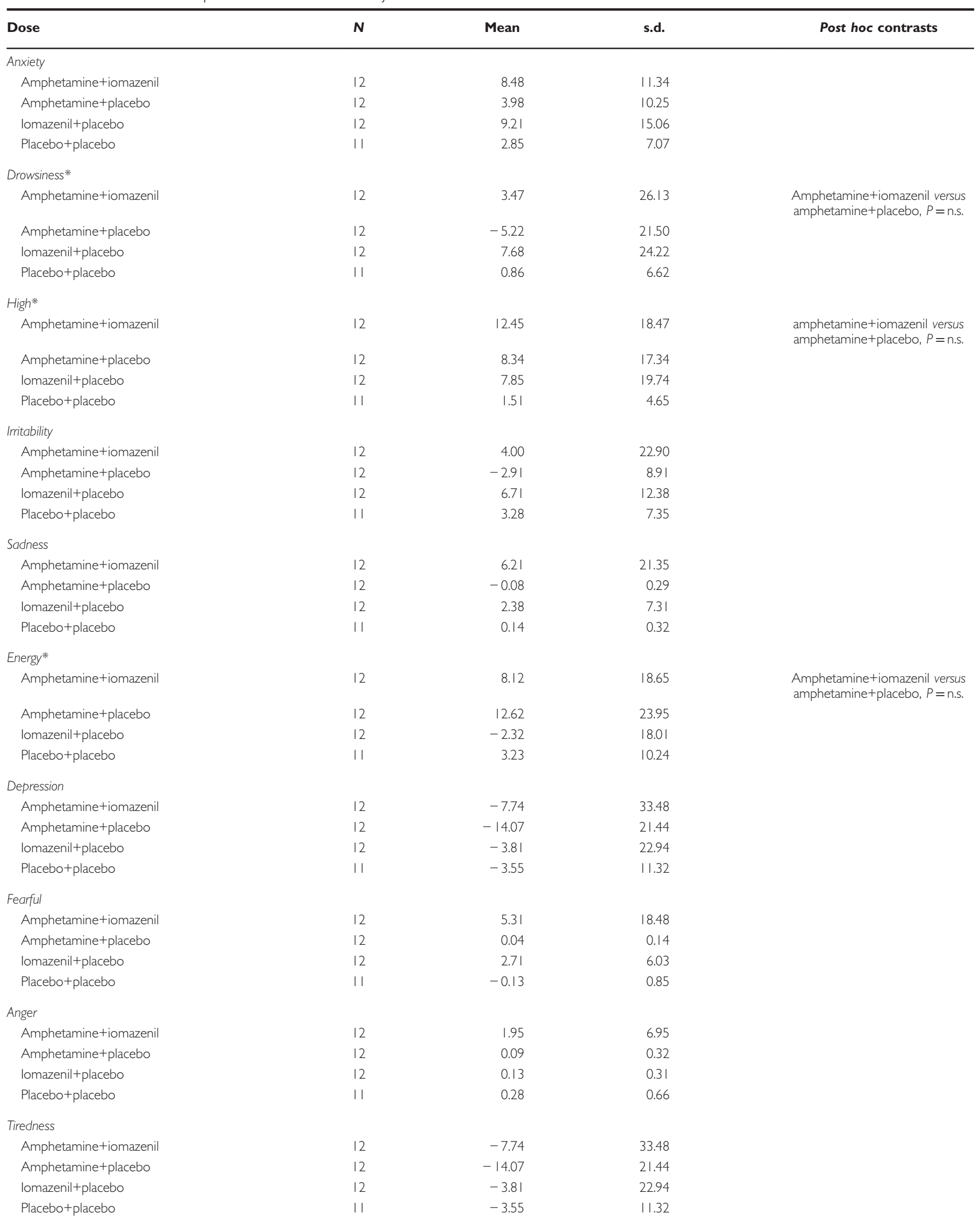

Mixed effects model with an unstructured variance-covariance matrix. Post hoc contrasts conducted only if initial analysis showed significance $* P<0.05$. 


\section{Strengths and Limitations}

This study has a number of strengths, including the doubleblind, randomized, crossover within subjects design, the use of well-validated measures, and the inclusion of only those subjects with subclinical response to amphetamine.

Although the observation that the largest increases in psychosis-like phenomena occurred with the combination of iomazenil and amphetamine provides some support for the mechanistic hypothesis, the lack of statistically significant interactive effects weakens that support. It is likely that the absence of statistically significant interactive effects $(P=0.12)$ is likely related to the small sample size. Furthermore, as only men were studied, the results may not generalize to women. Future studies with a larger sample size, which includes women, may permit a better assessment of interactive effects and also effects on individual symptoms.

\section{CONCLUSION}

In conclusion, the findings of the current study suggest that GABA deficit can increase vulnerability to amphetamineinduced psychosis-like phenomena. The precise anatomical and neurochemical mechanisms underlying the interactive effects of iomazenil and amphetamine are beyond the scope of current study. Future studies employing neuroreceptor imaging may provide more direct in vivo evidence whether iomazenil's enhancement of amphetamine-induced psychosis-like phenomena is related to its capacity to enhance amphetamine-induced DA release.

\section{FUNDING AND DISCLOSURE}

This research project was funded in part by grants from NARSAD Young Investigator Award (R09393) to KA. MR has in the past 3 years or currently received research grant support administered through the Yale University School of Medicine from Eli Lilly. DCD has in the past 3 years or currently received research grant support administered through the Yale University School of Medicine from AbbVieand Pfizer; he is a consultant for Bristol Meyers Squibb and Johnson and Johnson. JK is a consultant for AbbVie, Amgen, Astellas Pharma Global Development, AstraZeneca, Biomedisyn Corporation, Bristol-Myers Squibb, Eli Lilly and Company, Euthymics Bioscience,, and Neurovance, a subsidiary of Euthymics Bioscience, Janssen Research \& Development, Lundbeck Research USA, Novartis Pharma AG, Sage Therapeutics, Sunovion Pharmaceuticals, and Takeda Industries; is on the scientific advisory board for Lohocla Research Corporation, Mnemosyne Pharmaceuticals, Naurex, and Pfizer Pharmaceuticals; is a stockholder in Biohaven Medical Sciences; holds stock options in Mnemosyne Pharmaceuticals; holds patents for Dopamine and Noradrenergic Reuptake Inhibitors in Treatment of Schizophrenia, US Patent No. 5,447,948 (issued 5 September 1995), and Glutamate Modulating Agents in the Treatment of Mental Disorders, US Patent No. 8,778,979 (issued 15 July 2014); and filed a patent for Intranasal Administration of Ketamine to Treat Depression, US Application No. 14/197,767 (filed 5 March 2014). The remaining authors declare no conflict of interest.

\section{ACKNOWLEDGMENTS}

We wish to acknowledge support from the (1) NARSAD and (2) the Department of Veterans Affairs. We also thank Angelina Genovese, RNC, MBA; Michelle San Pedro, RN; Elizabeth O'Donnell, RN; Brenda Breault, RN, BSN; Sonah Yoo, RPh; Rachel Galvan, RPh; and Willie Ford of the Neurobiological Studies Unit at the VA Connecticut Healthcare System, West Haven Campus for their central contributions to the success of this project. This manuscript is dedicated to the memory of our dear friend and colleague, late Dr R Andrew Sewell.

\section{REFERENCES}

Abel KM, Allin MP, Hemsley DR, Geyer MA (2003). Low dose ketamine increases prepulse inhibition in healthy men. Neuropharmacology 44: 729-737.

Abi-Dargham A, Gil R, Krystal J, Baldwin RM, Seibyl JP, Bowers M et al (1998). Increased striatal dopamine transmission in schizophrenia: confirmation in a second cohort. Am J Psychiatry 155: 761-767.

Abi-Dargham A, van de Giessen E, Slifstein M, Kegeles LS, Laruelle M (2009). Baseline and amphetamine-stimulated dopamine activity are related in drug-naive schizophrenic subjects. Biol Psychiatry 65: 1091-1093.

Abi-Saab W, Seibyl JP, D'Souza DC, Karper LP, Gueorgueva R, Abi-Dargham A et al (2002). Ritanserin antagonism of m-chlorophenylpiperazine effects in neuroleptic-free schizophrenics patients: support for serotonin-2 receptor modulation of schizophrenia symptoms. Psychopharmacology (Berl) 162: 55-62.

Ahn K, Gil R, Seibyl J, Sewell RA, D'Souza DC (2011). Probing GABA receptor function in schizophrenia with iomazenil. Neuropsychopharmacology 36: 677-683.

Angrist BM, Gershon S (1970). The phenomenology of experimentally induced amphetamine psychosis-preliminary observations. Biol Psychiatry 2: 95-107.

Ball S, Busatto GF, David AS, Jones SH, Hemsley DR, Pilowsky LS et al (1998). Cognitive functioning and GABAA/benzodiazepine receptor binding in schizophrenia: a 123I-iomazenil SPET study. Biol Psychiatry 43: 107-117.

Bartlett EJ, Barouche F, Brodie JD, Wolkin A, Angrist B, Rotrosen J et al (1991). Stability of resting deoxyglucose metabolic values in PET studies of schizophrenia. Psychiatry Res 40: 11-20.

Beer HF, Blauenstein PA, Hasler PH, Delaloye B, Riccabona G, Bangerl I et al (1990). In vitro and in vivo evaluation of iodine123-Ro 16-0154: a new imaging agent for SPECT investigations of benzodiazepine receptors. J Nucl Med 31: 1007-1014.

Bell DS (1973). The experimental reproduction of amphetamine psychosis. Arch Gen Psychiatry 29: 35-40.

Benes FM (2000). Emerging principles of altered neural circuitry in schizophrenia. Brain Res Brain Res Rev 31: 251-269.

Benes FM, Berretta S (2001). GABAergic interneurons: implications for understanding schizophrenia and bipolar disorder. Neuropsychopharmacology 25: 1-27.

Breier A, Su TP, Saunders R, Carson RE, Kolachana BS, de Bartolomeis A et al (1997). Schizophrenia is associated with elevated amphetamine-induced synaptic dopamine concentrations: evidence from a novel positron emission tomography method. Proc Natl Acad Sci USA 94: 2569-2574.

Bremner JD, Krystal JH, Putnam FW, Southwick SM, Marmar C, Charney DS et al (1998). Measurement of dissociative states with the Clinician-Administered Dissociative States Scale (CADSS). J Trauma Stress 11: 125-136.

Brunner E, Domhof S, Langer F (2002). Nonparametric analysis of longitudinal data in factorial experiments. John Wiley \& Sons: New York, NY, pp 261. 
Busatto GF, Pilowsky LS, Costa DC, Ell PJ, David AS, Lucey JV et al (1997). Correlation between reduced in vivo benzodiazepine receptor binding and severity of psychotic symptoms in schizophrenia. Am J Psychiatry 154: 56-63.

Carr DB, Sesack SR (2000). GABA-containing neurons in the rat ventral tegmental area project to the prefrontal cortex. Synapse 38: 114-123.

Cherlyn SY, Woon PS, Liu JJ, Ong WY, Tsai GC, Sim K (2010). Genetic association studies of glutamate, GABA and related genes in schizophrenia and bipolar disorder: a decade of advance. Neurosci Biobehav Rev 34: 958-977.

D'Souza DC, Abi-Saab WM, Madonick S, Forselius-Bielen K, Doersch A, Braley G et al (2005). Delta-9-tetrahydrocannabinol effects in schizophrenia: implications for cognition, psychosis, and addiction. Biol Psychiatry 57: 594-608.

D'Souza DC, Gil RB, Zuzarte E, MacDougall LM, Donahue L, Ebersole JS et al (2006). gamma-Aminobutyric acid-serotonin interactions in healthy men: implications for network models of psychosis and dissociation. Biol Psychiatry 59: 128-137.

D'Souza DC, Perry E, MacDougall L, Ammerman Y, Cooper T, $\mathrm{Wu}$ YT et al (2004). The psychotomimetic effects of intravenous delta-9-tetrahydrocannabinol in healthy individuals: implications for psychosis. Neuropsychopharmacology 29: $1558-1572$.

Goto N, Yoshimura R, Moriya J, Kakeda S, Ueda N, IkenouchiSugita A et al (2009). Reduction of brain gamma-aminobutyric acid (GABA) concentrations in early-stage schizophrenia patients: 3 T Proton MRS study. Schizophr Res 112: 192-193.

Griffith JD, Oates JA, Cavanaugh J (1968). Paranoid episodes induced by drugs. J Am Med Assoc 205: 39.

Hashimoto T, Volk DW, Eggan SM, Mirnics K, Pierri JN, Sun Z et al (2003). Gene expression deficits in a subclass of GABA neurons in the prefrontal cortex of subjects with schizophrenia. J Neurosci 23: 6315-6326.

Hunkeler W, Mohler H, Pieri L, Polc P, Bonetti EP, Cumin R et al (1981). Selective antagonists of benzodiazepines. Nature 290: 514-516.

Innis RB, al-Tikriti MS, Zoghbi SS, Baldwin RM, Sybirska EH, Laruelle MA et al (1991). SPECT imaging of the benzodiazepine receptor: feasibility of in vivo potency measurements from stepwise displacement curves. J Nucl Med 32: 1754-1761.

Janowsky DS, el-Yousel MK, Davis JM, Sekerke HJ (1973). Provocation of schizophrenic symptoms by intravenous administration of methylphenidate. Arch Gen Psychiatry 28: 185-191.

Janowsky DS, Risch C (1979). Amphetamine psychosis and psychotic symptoms. Psychopharmacology (Berl) 65: 73-77.

Johnson EW, Woods SW, Zoghbi S, McBride BJ, Baldwin RM, Innis RB (1990). Receptor binding characterization of the benzodiazepine radioligand 125I-Ro16-0154: potential probe for SPECT brain imaging. Life Sci 47: 1535-1546.

Kalivas PW (1993). Neurotransmitter regulation of dopamine neurons in the ventral tegmental area. Brain Res Brain Res Rev 18: $75-113$.

Kay SR, Opler LA, Lindenmayer JP (1989). The Positive and Negative Syndrome Scale (PANSS): rationale and standardisation. Br J Psychiatry Suppl 7: 59-67.

Kegeles LS, Mao X, Stanford AD, Girgis R, Ojeil N, Xu X et al (2012). Elevated prefrontal cortex gamma-aminobutyric acid and glutamate-glutamine levels in schizophrenia measured in vivo with proton magnetic resonance spectroscopy. Arch Gen Psychiatry 69: 449-459.

Koreen AR, Lieberman JA, Alvir J, Chakos M (1997). The behavioral effect of $\mathrm{m}$-chlorophenylpiperazine (mCPP) and methylphenidate in first-episode schizophrenia and normal controls. Neuropsychopharmacology 16: 61-68.

Laruelle M, Abi-Dargham A, van Dyck CH, Gil R, D'Souza CD, Erdos J et al (1996). Single photon emission computerized tomography imaging of amphetamine-induced dopamine release in drug-free schizophrenic subjects. Proc Natl Acad Sci USA 93: 9235-9240.

Lewis DA, Curley AA, Glausier JR, Volk DW (2012). Cortical parvalbumin interneurons and cognitive dysfunction in schizophrenia. Trends Neurosci 35: 57-67.

Lewis DA, Hashimoto T, Volk DW (2005). Cortical inhibitory neurons and schizophrenia. Nat Rev Neurosci 6: 312-324.

Lieberman JA, Kane JM, Alvir J (1987a). Provocative tests with psychostimulant drugs in schizophrenia. Psychopharmacology (Berl) 91: 415-433.

Lieberman JA, Kane JM, Sarantakos S, Gadaleta D, Woerner M, Alvir J et al (1987b). Prediction of relapse in schizophrenia. Arch Gen Psychiatry 44: 597-603.

Murphy BL, Arnsten AF, Goldman-Rakic PS, Roth RH (1996). Increased dopamine turnover in the prefrontal cortex impairs spatial working memory performance in rats and monkeys. Proc Natl Acad Sci USA 93: 1325-1329.

Ohnuma T, Augood SJ, Arai H, McKenna PJ, Emson PC (1999). Measurement of GABAergic parameters in the prefrontal cortex in schizophrenia: focus on GABA content, GABA(A) receptor alpha-1 subunit messenger RNA and human GABA transporter-1 (HGAT-1) messenger RNA expression. Neuroscience 93: 441-448.

Ongur D, Prescot AP, McCarthy J, Cohen BM, Renshaw PF (2010). Elevated gamma-aminobutyric acid levels in chronic schizophrenia. Biol Psychiatry 68: 667-670.

Rowland LM, Kontson K, West J, Edden RA, Zhu H, Wijtenburg SA et al (2013). In vivo measurements of glutamate, GABA, and NAAG in schizophrenia. Schizophr Bull 39: 1096-1104.

Schroder J, Bubeck B, Demisch S, Sauer H (1997). Benzodiazepine receptor distribution and diazepam binding in schizophrenia: an exploratory study. Psychiatry Res 68: 125-131.

Schubiger P, Hasler P (eds) (1989). Iomazenil and other Brain Receptor Tracers for SPECT. Proceedings of the 6th Bottstein Colloquim: Wurenlingen/Villigen Switzerland.

Sesack SR, Carr DB, Omelchenko N, Pinto A (2003). Anatomical substrates for glutamate-dopamine interactions: evidence for specificity of connections and extrasynaptic actions. Ann NY Acad Sci 1003: 36-52.

Tallman JF, Gallager DW (1985). The GABA-ergic system: a locus of benzodiazepine action. Annu Rev Neurosci 8: 21-44.

Tam SY, Roth RH (1990). Modulation of mesoprefrontal dopamine neurons by central benzodiazepine receptors. I. Pharmacological characterization. J Pharmacol Exp Ther 252: 989-996.

Tayoshi S, Nakataki M, Sumitani S, Taniguchi K, Shibuya-Tayoshi S, Numata $S$ et al (2010). GABA concentration in schizophrenia patients and the effects of antipsychotic medication: a proton magnetic resonance spectroscopy study. Schizophr Res 117: 83-91.

Theile JW, Morikawa H, Gonzales RA, Morrisett RA (2011). GABAergic transmission modulates ethanol excitation of ventral tegmental area dopamine neurons. Neuroscience 172: 94-103.

Tzschentke TM (2001). Pharmacology and behavioral pharmacology of the mesocortical dopamine system. Prog Neurobiol 63: 241-320.

Van Bockstaele EJ, Pickel VM (1995). GABA-containing neurons in the ventral tegmental area project to the nucleus accumbens in rat brain. Brain Res 682: 215-221.

Verhoeff NP, Soares JC, D'Souza CD, Gil R, Degen K, Abi-Dargham A et al (1999). [123I]Iomazenil SPECT benzodiazepine receptor imaging in schizophrenia. Psychiatry Res 91: 163-173.

Volk DW, Austin MC, Pierri JN, Sampson AR, Lewis DA (2000). Decreased glutamic acid decarboxylase67 messenger RNA expression in a subset of prefrontal cortical gamma-aminobutyric acid neurons in subjects with schizophrenia. Arch Gen Psychiatry 57: 237-245.

Volk DW, Lewis DA (2002a). Impaired prefrontal inhibition in schizophrenia: relevance for cognitive dysfunction. Physiol Behav 77: 501-505. 
Volk DW, Pierri JN, Fritschy JM, Auh S, Sampson AR, Lewis DA (2002b). Reciprocal alterations in pre- and postsynaptic inhibitory markers at chandelier cell inputs to pyramidal neurons in schizophrenia. Cereb Cortex 12: 1063-1070.

Westerink BH, Kwint HF, deVries JB (1996). The pharmacology of mesolimbic dopamine neurons: a dual-probe microdialysis study in the ventral tegmental area and nucleus accumbens of the rat brain. J Neurosci 16: 2605-2611.
Woo TU, Whitehead RE, Melchitzky DS, Lewis DA (1998). A subclass of prefrontal gamma-aminobutyric acid axon terminals are selectively altered in schizophrenia. Proc Natl Acad Sci USA 95: 5341-5346.

Yoon JH, Maddock RJ, Rokem A, Silver MA, Minzenberg MJ, Ragland JD et al (2010). GABA concentration is reduced in visual cortex in schizophrenia and correlates with orientation-specific surround suppression. J Neurosci 30: 3777-3781.

Supplementary Information accompanies the paper on the Neuropsychopharmacology website (http://www.nature.com/npp) 